\title{
Effect of a quality-improving codend on size selectivity and catch patterns of cod in bottom trawl fishery
}

\author{
Brinkhof, Jesse; Herrmann, Bent; Larsen, Roger B.; Malta, Tiago Alexandre Matias da Veiga
}

Published in:

Canadian Journal of Fisheries and Aquatic Sciences

Link to article, DOI:

10.1139/cjfas-2018-0402

Publication date:

2019

Document Version

Peer reviewed version

Link back to DTU Orbit

Citation (APA):

Brinkhof, J., Herrmann, B., Larsen, R. B., \& Malta, T. A. M. D. V. (2019). Effect of a quality-improving codend on size selectivity and catch patterns of cod in bottom trawl fishery. Canadian Journal of Fisheries and Aquatic Sciences, 76(11), 2110-2120. https://doi.org/10.1139/cjfas-2018-0402

\section{General rights}

Copyright and moral rights for the publications made accessible in the public portal are retained by the authors and/or other copyright owners and it is a condition of accessing publications that users recognise and abide by the legal requirements associated with these rights.

- Users may download and print one copy of any publication from the public portal for the purpose of private study or research.

- You may not further distribute the material or use it for any profit-making activity or commercial gain

- You may freely distribute the URL identifying the publication in the public portal 
1 Effect of a quality-improving codend on size selectivity and catch patterns of 2 cod in bottom trawl fishery

3 Jesse Brinkhof ${ }^{1 *}$, Bent Herrmann ${ }^{1,2}$, Roger B. Larsen ${ }^{1}$, Tiago Veiga-Malta ${ }^{3}$

$4{ }^{1}$ Norwegian College of Fishery and Aquatic Science, University of Tromsø, 9037 Breivika, Tromsø, Norway

$5 \quad 2$ SINTEF Ocean, Fishing Gear Technology, Willemoesvej 2, 9850 Hirtshals, Denmark

$6 \quad{ }^{3}$ DTU Aqua, Technical University of Denmark, Hirtshals, Denmark

7 * Corresponding author, Tel. +47 97662167, Email: jesse.brinkhof@uit.no (J. Brinkhof)

\section{Abstract}

9 A new codend concept developed and tested exhibited significantly improved quality of caught $10 \operatorname{cod}$ (Gadus morhua) compared to that of the conventional codend used in the Barents Sea 11 bottom trawl fishery. However, the design of the new quality-improving codend raised concerns 12 about its size selectivity and the possibility that higher retention probability could negatively 13 impact the catch pattern by increasing the proportion of undersized cod. Therefore, the goal of 14 this study was to quantify and compare the size selectivity and catch pattern for cod when 15 deploying respectively the conventional and new quality-improving codend in the Barents Sea 16 bottom trawl fishery. The new quality-improving codend had significantly lower relative size 17 selectivity than the conventional codend, but no significant difference in the catch patterns was 18 detected in the trawl. Further, estimation of the total size selectivity in the trawl revealed that 19 the increased retention of small cod when using the quality-improving codend was minor. 20 Hence, despite the reduced selectivity, the quality-improving codend can be used with low risk 21 of retaining small cod.

22 Keywords: Codend, bottom trawl, cod, sequential codend, size selectivity

\section{Introduction}

24 Trawl caught fish has been associated with deteriorated quality (Digre et al. 2010; Rotabakk et al. 2011). In the Barents Sea bottom trawl fishery, about $70 \%$ of the annual quota of Northeast Arctic cod (Gadus morhua L.) is caught with bottom trawls (ICES 2015). The technical regulations are largely designed to minimize the amount of bycatch and consist mainly of minimum codend mesh size regulations and the compulsory use of a size selective sorting grid (Norwegian Directorate of Fisheries 2018). An important factor that is believed to contribute to catch defects is the large meshes that are regulated by law. Large meshes are required to ensure the possibility of escapement of undersized fish that do not escape through the mandatory size 
selective sorting grid (Sistiaga et al. 2016a; Brinkhof et al. 2018a). Moreover, codends often are made from coarse materials with a large mesh size, causing high water flow, and thus they do not create a lenient and benign environment for fish.

Brinkhof et al. (2018a) recently described a new codend concept, called a dual sequential codend, that demonstrated improved quality of trawl-caught cod. They reported that the probability of catching cod without any visual quality defect was five times higher when using the sequential codend, i.e. $18 \%$ compared to $3 \%$ for cod retained in the conventional codend. The codend was designed so that it would maintain the size selective properties required during towing at the seabed while also providing a more quality-preserving environment for the catch during haul-back. In the dual sequential codend, the fish are retained in the anterior codend segment during towing, and this segment has the size selective attributes required by law (i.e., minimum mesh size of $130 \mathrm{~mm}$ ). The entrance to the posterior codend segment is kept closed with a hydrostatic codend releaser during fishing, and it is opened at a pre-set depth during haul-back. This posterior quality-improving codend segment, which the catch enters during haul-back, consists entirely of small meshes made of thick twine (Ø3 mm) (Brinkhof et al. 2018a). Hence, it is reasonable to assume that when the catch enters the posterior codend segment, the escapement of undersized fish is no longer possible. This could potentially alter the size selective properties of the codend compared to a conventional codend, from which fish are able to escape during haul-back. If few or no fish escape during the haul-back phase regardless of codend type, the total selectivity of the fishing process would be unaffected by the new codend. However, if fish generally escape from the conventional codend during the haul-back phase, the new codend could potentially affect the overall size selectivity of the fishing process. This would mean that the dual sequential codend would likely retain more undersized fish compared to a conventional codend. Previous studies have documented an ongoing selection process during haul-back (Madsen et al. 2008; Grimaldo et al. 2009; Herrmann et al. 2013; Brinkhof et al. 2017), and therefore it is highly relevant to investigate if the new codend causes a reduced size selection. Hence, the aim of this study was to investigate the size selectivity and catch pattern for cod in the Barents Sea bottom trawl fishery when applying a conventional codend and the new dual sequential codend. Specifically, the following research questions were addressed:

- Will the sequential codend have a similar size selection as the conventional codend?

- Is there any effect on the length-dependent catch patterns between the trawl equipped with the conventional and dual sequential codend? 
65

66

- How will the total size selectivity in the trawl be when employing the conventional and sequential codend, and will the retention risk for small cod be sufficiently low when using the sequential codend?

\section{Materials and methods}

\section{Study area, trawl rigging, and data collection}

To address the research questions experimental fishing trials were conducted between 27 February and 5 March 2018 onboard the R/V "Helmer Hanssen" (63.8 m, 4080 HP) along the coast of north Norway in the southern Barents Sea (N 71 $21^{\prime}$ E $\left.23^{\circ} 43^{\prime}-\mathrm{N} 71^{\circ} 21^{\prime} \mathrm{E} 24^{\circ} 24^{\prime}\right)$. The research questions necessitated the quantification of the relative size selection between the two codends, the catch patterns that would be obtained from applying them in the Barents Sea fishery, and the total size selection in the trawl when equipped with respectively the conventional and dual sequential codend. To estimate the total selectivity in the trawl and the influence on the catch pattern if the traditional codend is replaced by the dual sequential codend it is necessary that the trawls were rigged as in the commercial fishery, which includes a size selective sorting grid and codends with a mesh size according to the legislation.

Optimally, to answer the three research objectives one would use two different trawl riggings with a cover to retain the escapees from both the grid section and codend. However, due to the length of the sequential codend $(21 \mathrm{~m})$, this would require using a cover of at least $45 \mathrm{~m}$ in length. However, a cover of $45 \mathrm{~m}$ in length is far longer than previously deployed on the research vessel, which was $14 \mathrm{~m}$ long (Grimaldo et al. 2017). Based on this there was concerns if such a cover could function and if it could be handled on the vessel. Therefore, it was decided to use a different experimental design based on deploying three different trawl riggings (design setups) during the cruise (Fig 1). The first two were identical trawls rigged as in the commercial fishery; one trawl equipped with a conventional codend and the second with the dual sequential codend. The trawls were deployed alternately without covers, enabling a paired structural catch comparison on the resulting catch data from these hauls for the estimation of the relative size selectivity between the two codends with best possible statistical power (explained in section for analysis) (Fig 1). The data obtained from alternating the trawls also enabled estimation of the catch patterns in the trawls with the two different codends. However, the total selectivity in each of the two trawls, i.e. grids and codend, could not be estimated alone from these hauls due to the lack of the retention of the escapees through the grids and codends. Therefore, during the last part of the cruise the trawl with the conventional codend was equipped with covers over 
the grids and codend to ensure that all cod entering the aft of the trawl (from grid to codline) was retained (Fig. 1). The series of hauls conducted with this third gear setup enabled estimation of the population size structure in the area where the two first gear setup were fished (Fig. 1). Combining the collected catch data from setup 1 (DS1) and 2 (DS2) with setup 3 (DS3) (Fig. 1) enabled estimation of the total gear size selection for both the trawl with the conventional codend and the sequential codend applying an unpaired estimation method (Sistiaga et al. 2016b). It was not possible to alternate all three setups on the vessel as this would have required handling three trawls. Therefore, for practical reasons the experimental setup described above was the best compromise. Fig. 1 presents how the three different design setups contribute both alone and in combination with each other to answer the outlined research questions.

\section{FIG 1.}

The trawls were equipped with Injector Scorpion $\left(3100 \mathrm{~kg}, 8 \mathrm{~m}^{2}\right)$ otter boards with $3 \mathrm{~m}$ long backstraps followed by a $7 \mathrm{~m}$ long chain, which was linked to the $60 \mathrm{~m}$ long sweeps. To reduce abrasion, an $\varnothing 53 \mathrm{~cm}$ bobbin was inserted in the center of the sweeps. The $46.9 \mathrm{~m}$ long ground gear consisted of a $14 \mathrm{~m}$ chain $(\varnothing 19 \mathrm{~mm})$ with three bobbins $(\varnothing 53 \mathrm{~cm})$ on each side and an 18.9 $\mathrm{m}$ long rockhopper gear with $\emptyset 53 \mathrm{~cm}$ rubber discs. The ground gear was attached to the 19.2 $\mathrm{m}$ long fishing line of the trawl. The two trawls, Alfredo No. 3, were built entirely out of polyethylene with a $155 \mathrm{~mm}$ mesh size. The headline of the trawls was $35.6 \mathrm{~m}$ long and equipped with 170 floats (Ø8“'). Both trawls were equipped with a flexigrid with $55 \mathrm{~mm}$ bar spacing, which is one of the compulsory sorting grids in this fishery (Sistiaga et al. 2016a).

The section with the flexigrid in the conventionally configured trawl was followed by an $9 \mathrm{~m}$ long extension piece (150 mm mesh size), which was preceded by a $11 \mathrm{~m}$ long two-panel codend consisting of single-braided Ø8 mm Euroline Premium (Polar Gold) netting in the under panel and double-braided Ø4 mm polyethylene in the upper panel, with a mean ( \pm SD) mesh size of $133 \pm 5.1 \mathrm{~mm}$. The second trawl was equipped with a dual sequential codend mounted directly to the flexigrid section (Brinkhof et al. 2018a) (Fig. 2). The first codend segment was built the same way as the conventional codend, and had a mean $( \pm \mathrm{SD})$ mesh size of $139 \pm 2.5$ $\mathrm{mm}$. The second codend segment, which was the quality-preserving section (Brinkhof et al. 2018a), was $10 \mathrm{~m}$ long and consisted of four panels with a nominal mesh size of $6 \mathrm{~mm}$ (1440 meshes in circumference, 360 meshes in each panel) (Fig. 2). The two codend segments were connected as a 2-panel codend. The codend segment was strengthened with an outer knotless codend (Ultracross) with $112 \mathrm{~mm}$ nominal mesh size (90 meshes in circumference) and four lastridge ropes, which were $5 \%$ shorter than the netting in the codend segment (Fig. 2). Because 
130 this codend segment does not meet the size selective properties required due to its small mesh 131 size, the entrance of the codend was closed during fishing at the seabed. During haul-back, the 132 entrance of the codend segment was opened by detaching a choking rope using a hydrostatic 133 codend release mechanism (produced by www.fosstech.no) (Fig. 2). The catch releaser was 134 charged during descent by the ambient pressure. The accumulated pressure was used to open a 135 release hook during the ascent, which then detached the choking rope at a pre-set depth of 120 $136 \mathrm{~m}$, thereby enabling free passage of fish from the selective codend segment into the quality137 improving codend segment.

\section{FIG. 2}

139 As described above during the second part of the cruise, a group of hauls were conducted with 140 the trawl with the conventional codend, but all escape outlets were covered with covers to retain 141 all escaping fish that entered the trawl, DS3 in Fig. 1. The small meshed cover placed over the 142 flexigrid was similar to that used by Sistiaga et al. (2016a), whereas the cover placed over the 143 codend was the same as that used by Grimaldo et al. (2017). The total length of all cod retained 144 in the trawls was measured to the nearest lower centimeter.

\section{Model and method for quantifying missing size selectivity in the sequential codend}

146 This section develops a model and method for quantifying the size selection that during the 147 haul-back phase will be missing in the sequential codend compared to the conventional codend. 148 The method is based on comparing the catches obtained with the two trawl setups (DS1 and 149 DS2), and relating the observed ratio in catches to the missing size selection (i.e. the size 150 selectivity in the conventional codend that is lacking in the sequential codend) (Fig. 1). Because 151 the conventional codend and sequential codend were each used every second haul in the same 152 area, the collected catch data were treated as paired catch comparison data (Krag et al. 2015).

153 Based on the approach described by Brinkhof et al. (2017b), the size selectivity process during 154 trawling with both the conventional and sequential codends can be regarded as a temporal 155 sequential process consisting of a towing phase $(t)$ followed by a haul-back phase $(h)$. The haul156 back selectivity phase can be viewed as a spatial sequential process, first with selectivity in the 157 gear before the catch build up zone in the codend $(a)$ followed by a selectivity process in the 158 codend catch build up zone $(b)$. Based on these considerations, the total selectivity process with 159 the conventional codend $r_{c}(l)$ can be modelled by (Fig. 3):

$r_{c}(l)=r t_{c}(l) \times r h a_{c}(l) \times r h b_{c}(l)$ 
161 whereas the total size selectivity with the sequential codend $r_{s}(l)$ can be modelled by (Fig. 3):

$r_{s}(l)=r t_{s}(l) \times r h a_{s}(l) \times r h b_{s}(l)$

163 where $r t$ denotes size selectivity during towing; rha denotes size selection in the anterior and 164 codend sections in front of the catch build up zone during haul-back, which includes the sorting 165 grid and extension piece; and $r h b$ denotes size selectivity in the catch build up zone of the 166 codend during haul-back (Fig. 3). Let $n c_{l i}$ and $n s_{l i}$ be the numbers of fish in length class $l$ caught 167 in haul pair $i$ in the conventional codend and the sequential codend, respectively. Based on the 168 group of $a$ paired hauls, we can quantify the experimental average catch comparison rate $C C_{l}$ 169 (Herrmann et al. 2017) as follows:

$C C_{l}=\frac{\sum_{i=1}^{a} \frac{n c_{l i}}{q c_{i}}}{\sum_{i=1}^{a} \frac{n c_{l i}}{q c_{i}}+\sum_{i=1}^{a} \frac{n s_{l i}}{q s_{i}}}$

171 where $q c_{i}$ and $q s_{i}$ are sampling factors introduced to account for unequal towing time between 172 the conventional $\left(t c_{i}\right)$ and sequential $\left(t s_{i}\right)$ codend within each pair $i$ fished. Specifically, $q c_{i}$ and $173 q s_{i}$ were set at:

$$
\begin{aligned}
q c_{i} & =\frac{t c_{i}}{\max \left(t c_{i}, t s_{i}\right)} \\
q s_{i} & =\frac{t s_{i}}{\max \left(t c_{i}, t s_{i}\right)}
\end{aligned}
$$

175 According to Eq. 4 the calculation of the sampling factors is based on the assumption that the 176 number of cod entering is expected to increase proportional with the fishing effort. With equal towing speed within the pairs, the fishing effort can be considered to be proportional with the

178 towing time. Within the pairs, the haul with the longest towing time will have a sampling factor 179 equal to 1.0, while the other tow will have a sampling factor which is scaled down with the ratio 180 between the two towing times.

181 The next step is to express the relationship between the catch comparison rate $C C(l)$ and the 182 size selection process for the conventional codend $r_{c}(l)$ and the sequential codend $r_{s}(l)$. In this 183 process, assume that the total amount of fish $n_{l}$ in length class $l$ enters the trawl with the 184 conventional or sequential codend (Fig. 3).

185 FIG. 3 
$186 \mathrm{SP}$ is the proportion of fish entering the aft part of the trawl with the conventional codend 187 compared to the sequential codend. SP is assumed to be length independent. Therefore, the 188 expected values for $\sum_{i=1}^{a} \frac{n c_{l i}}{q c_{i}}$ and $\sum_{i=1}^{a} \frac{n s_{l i}}{q s_{i}}$, respectively, are:

$$
\begin{gathered}
\sum_{i=1}^{a} \frac{n c_{l i}}{q c_{i}}=n_{l} \times S P \times r_{c}(l) \\
\sum_{i=1}^{a} \frac{n s_{l i}}{q s_{i}}=n_{l} \times(1-S P) \times r_{S}(l)
\end{gathered}
$$

190 Based on models (1) to (5) and Fig. 3, the theoretical catch comparison rate $C C(l)$ becomes:

$$
C C(l)=\frac{n_{l} \times S P \times r t_{c}(l) \times r h a_{c}(l) \times r h b_{c}(l)}{n_{l} \times S P \times r t_{c}(l) \times r h a_{c}(l) \times r h b_{c}(l)+n_{l} \times(1-S P) \times r t_{s}(l) \times r h a_{s}(l) \times r h b_{s}(l)}
$$

192 Next, the following assumptions are introduced:

$$
\begin{aligned}
r t_{c}(l) & \approx r t_{s}(l) \\
r h a_{c}(l) & \approx r h a_{s}(l) \\
r h b_{s}(l) & =1.0
\end{aligned}
$$

194 The first condition assumes that the size selection between the two trawls is approximately 195 equal during the towing phase because the grid systems are identical and the active codends 196 during towing are designed to have equal size selectivity. The second condition assumes that 197 the size selectivity in front of the codends during haul-back is approximately equal based on 198 the use of the same grid systems and mesh size in the netting. The last condition assumes that 199 the active codend in the quality-improving codend during haul-back will retain all sizes of cod 200 due to the small mesh size.

201 Based on the three assumptions equation (6) can be simplified to:

$202 C C(l)=\frac{S P \times r h b_{c}(l)}{S P \times r h b_{c}(l)+1-S P}$

203 With (8) we have obtained a direct relationship between the size selection process $\left(r h b_{c}(l)\right)$ that 204 will be missing with the sequential codend and the catch comparison rate $(C C(l))$. Therefore, 205 this size selectivity then can be assessed based on estimating the catch comparison rate. Based 206 on combining equations (1) and (2) while using the assumptions (7) we arrive at that $r h b_{c}(l)$ 207 also quantifies the ratio between the size selectivity in the trawl with the conventional codend 208 (DS1) and the trawl with the sequential codend (DS2). Therefore, the size selectivity in the trawl 209 with the sequential codend can be expressed in terms of the selectivity in the trawl with the 210 conventional codend multiplied by a factor that is one divided by the missing selectivity:

$211 \quad r_{s}(l)=\frac{1.0}{r h b_{c}(l)} \times r_{c}(l)(9)$ 
212 Therefore, if some cod first escape through the meshes in the aft of the codend during haul213 back the use of the sequential codend will scale the retention probability for the total trawl 214 process up by 1.0 divided the missing haul-back selectivity.

215 We estimated the average missing size selectivity with the sequential codend using maximum 216 likelihood methods by minimizing the following equation with respect to the parameters 217 describing $C C(l)$, which in addition to $S P$, include the parameters in the model that we apply 218 for $r h b_{c}(l)$ :

$-\sum_{l}\left\{\sum_{i=1}^{a}\left\{\frac{n c_{l i}}{q c_{i}} \times \ln (C C(l))\right\}+\sum_{i=1}^{a}\left\{\frac{n s_{l i}}{q s_{i}} \times \ln (1-C C(l)\}\right\}\right.$

220 Often, the size selection for diamond mesh codends is described using a Logit size selectivity 221 model (Wileman et al. 1996):

$r_{\text {logit }}\left(l, l_{50}, S R\right)=\frac{\exp \left(\frac{\ln (9)}{S R} \times\left(l-l_{50}\right)\right)}{1+\exp \left(\frac{\ln (9)}{S R} \times\left(l-l_{50}\right)\right)}$,

223 where $L 50$ is the length of fish with a $50 \%$ probability of being retained during the selection 224 process and $S R$ is $L 75-L 25$. Thus, we used model (11) as a starting point. However, we also 225 must consider the potential situation where only a fraction of the fish in the codend is capable 226 of attempting to escape, which is obtained by considering the assumed length-independent 227 contact parameter $C$ (Herrmann et al. 2013) as follows:

$r_{C l o g i t}\left(l, C, l_{50}, S R\right)=1-C+C \times r_{\text {logit }}\left(l, l_{50}, S R\right)=1-\frac{C}{1+\exp \left(\frac{\ln (9)}{S R} \times\left(l_{50-l)}\right)\right.}$

229 However, without assuming any specific model for the missing size selectivity $\left(r h b_{c}(l)\right)$, such 230 as equations (11) or (12), we also could formally determine whether there is evidence of missing 231 size selectivity with the sequential codend by analyzing the catch comparison data. The null 232 hypothesis was that the size selectivity of the two codend types was equal, which implies that $233 r h b_{c}(l)=1.0$ for all $l$. Thus, based on equation $(8), C C(l)=S P$. We first tested whether this 234 hypothesis could be rejected based on the collected data by estimating the value of SP under 235 this hypothesis based on equation (10) and then calculating the $p$-value to obtain at least as big 236 discrepancy as observed between the experimental catch comparison data and the model by 237 chance. If this $p$-value was below 0.05 , we could reject the null hypothesis unless the data 238 appeared to exhibit over-dispersion, which would be indicated by lack of any fish length239 dependent pattern in the deviation between the modeled catch comparison rate and the 240 experimental data points. In case the null hypothesis is rejected, thereby providing evidence for 
241 missing size selectivity, we then quantified this selectivity using models (11), (12), and (6). 242 This process included testing whether using models (11) and (12) in (6) could describe the 243 observed catch comparison data sufficiently well ( $p$-value $>0.05)$, and we employed these 244 models to estimate the parameters with equation (10). The parameters $S P, L 50$, and $S R$ were 245 estimated with equation (11), while the estimation in equation (12) included the additional 246 parameter $C$. If both equations (11) and (12) could describe the experimental data, then the one 247 with the lowest Akaike's information criterion (AIC) value (Akaike 1974) would be selected 248 for modeling the missing size selectivity. We estimated $95 \%$ confidence intervals (CIs) for the 249 catch comparison curve and the resulting sequential codend size selection curve using double 250 bootstrapping for paired catch comparison data (Lomeli et al. 2018). We performed 1000 251 bootstrap replicates.

252 In addition to modelling the experimental catch comparison rate in (10) based on (8) using (11) 253 or (12), we also tested the empirical modelling approach that often is used in catch comparison 254 studies (Krag et al. 2014, 2015; Herrmann et al. 2017, 2018):

$255 C C(l, \boldsymbol{v})=\frac{\exp (f(l, \boldsymbol{v}))}{1.0+\exp (f(l, \boldsymbol{v}))}$

256 where $f$ is a polynomial of order 4 with coefficients $v_{0}, \ldots, v_{4}$ so $v=\left(v_{0}, \ldots, v_{4}\right)$. Leaving out one 257 or more of parameters $v_{0} \ldots v_{4}$, we obtained 31 additional models that were considered as 258 potential models to describe $C C(l, v)$. Based on these models, model averaging was applied to 259 describe $C C(l, v)$ according to how likely the individual models were compared to each other 260 (Burnham and Anderson 2002). The models were ranked in order of AIC value following the 261 procedure described by Katsanevakis (2006) and Herrmann et al. (2017), and those within +10 262 of the value of the model with the lowest AIC value were included in the combined model 263 (Akaike 1974; Burnham and Anderson 2002).

264 Estimation of difference in size-dependent catch pattern between the two codends

265 The actual difference in catch pattern between the two codend types was assessed by calculating 266 the difference in the population structure of the catch for the two codends (Fig 1). The length267 dependent population frequencies retained in the codends were calculated as follows:

268

$$
\begin{gathered}
f c_{l}=\frac{\sum_{i=1}^{a} n c_{l i}}{\sum_{l} \sum_{i=1}^{a} n c_{l i}} \\
f s_{l}=\frac{\sum_{i=1}^{a} n s_{l i}}{\sum_{l} \sum_{i=1}^{a} n s_{l i}}
\end{gathered}
$$


where $f c_{l}$ and $f s_{l}$ are the frequencies of fish at length $l$ (in length class with middle point $l$ ) retained in the conventional codend and the sequential codend, respectively. The 95\% confidence interval (CI) was obtained using the double bootstrapping technique described above.

To infer the effect of changing from the conventional to the sequential codend on population size structures, the change in the length-dependent frequency $\Delta f_{l}$ was estimated as:

$\Delta f_{l}=f s_{l}-f c_{l}$

Efron $95 \%$ percentile confidence limits (Efron 1982) for $\Delta f_{l}$ were obtained based on the two bootstrap populations of results (1000 bootstrap repetitions in each) for both $f s_{l}$ and $f c_{l}$. As they are obtained independently, a new bootstrap population of results was created for $\Delta f_{l}$ as follows:

$\Delta f_{l i}=f s_{l i}-f c_{l i} i \in[1 \ldots 1000]$

where $i$ denotes the bootstrap repetition index. Because the bootstrap resampling was random and independent for the two groups of results, it is valid to generate the bootstrap population of results for the difference based on (16) using the two independently generated bootstrap files (Larsen et al. 2018).

\section{Estimation of the total size selectivity in the two trawls}

The total size selectivity $r_{c}(l)$ for the trawl equipped with the traditional codend was estimated by combining the catch data $n c_{l i}$ for the $a$ uncovered hauls conducted using the conventional codend (DS1) with the catch data $n f_{l j}$ for the $b$ covered control hauls (DS3) with full trawl retention by minimizing (16) following the procedure described in Sistiaga et al. (2016b) for estimating the selectivity of unpaired trawl data (Fig. 1):

$$
-\sum_{\{}\left\{\sum_{i=1}^{a}\left\{\frac{n c_{l i}}{q c_{i}} \times \ln \left(\frac{S P \times r_{c}(l)}{S P \times r_{c}(l)+1-S P}\right)\right\}+\sum_{j=1}^{b}\left\{\frac{n f_{l j}}{q f_{j}} \times \ln \left(\frac{1-S P}{S P \times r_{c}(l)+1-S P}\right\}\right\}\right.
$$

Similarly, the total size selectivity $r_{s}(l)$ for the trawl equipped with the quality-improving codend was estimated by combining the catch data $n s_{l i}$ for the $a$ uncovered hauls conducted using the quality-improving codend with the catch data for the $b$ covered control hauls by minimizing the following:

$-\sum_{l}\left\{\sum_{i=1}^{a}\left\{\frac{n s_{l i}}{q s_{i}} \times \ln \left(\frac{S P \times r_{s}(l)}{S P \times r_{s}(l)+1-S P}\right)\right\}+\sum_{j=1}^{b}\left\{\frac{n f_{l j}}{q f_{j}} \times \ln \left(\frac{1-S P}{S P \times r_{s}(l)+1-S P}\right\}\right\}\right.$ 
297 For both $r_{c}(l)$ and $r_{s}(l)$ we considered both the Logit (10) and Clogit (11) size selection models 298 and used the one with the lowest AIC value. Only in case of poor fit statistics (p-value $<0.05)$ 299 would we consider other size selection models.

300 All estimates were obtained using the software tool SELNET, which was developed for 301 estimating size selectivity and catch comparisons for fishing gears (Herrmann et al. 2013). The 302 estimates were then exported and graphically represented using R (R Core Team 2013).

\section{Results}

304 During the cruise a total of 20 valid trawls were conducted. Sixteen hauls were conducted 305 alternately using the two different codends ( 8 haul pairs) in order to estimate the potential 306 missing size selectivity of the sequential codend (Table 1, DS1 and DS2 in Fig. 1). Four 307 additional control hauls were conducted with covers over the flexigrid and codend (DS3 in Fig. 308 1) to obtain a length-based abundancy measure of the fish entering the trawl during the 309 experimental fishing. To ensure that the fish were caught from the same population and to 310 minimize the between-haul variance, towing area and depth were kept as constant as possible, 311 as was the number of days spent collecting the data (Table 1, Fig. 4). In total, 6889 cod were 312 caught, 2439 of which were retained in the conventional codend and 3068 of which were 313 retained in the dual sequential codend. The remaining $1382 \mathrm{cod}$ were caught in the four control 314 hauls.

\section{TABLE 1}

$316 \quad$ FIG. 4

\section{Estimation of the missing size selectivity}

318 Figure 5a shows the length distribution of all cod caught in the conventional codend and the 319 dual sequential codend. Cod in the size range between 40 and $119 \mathrm{~cm}$ were retained during the 320 fishing trials. The p-value for the null hypothesis model $\left(\mathrm{H}_{0}\right)$ was 0.0033 , which means we could reject this model (i.e., no difference in the size selection between the conventional and dual sequential codends) (Table 2). A difference in size selectivity between the two codends was supported by the discrepancy between catch comparison curves for the $\mathrm{H}_{0}$ model and the 324 length-dependent pattern in the experimental data (Fig. 5b). Being a length-independent catch 325 comparison rate, the $\mathrm{H}_{0}$ model curve is equal to that of the SP (i.e., 0.4625). The empirical 326 model provided good fit statistics and fitted the experimental data points nicely (Fig. 5c, Table 327 2). However, empirical models cannot provide selection parameters. Therefore, two structural 
models were investigated. Although the Clogit model provided a significantly improved model fit compared to the $\mathrm{H}_{0}$ model, the Logit model provided the best model fit (i.e., lowest AIC value) (Table 2). The catch comparison curve from the Logit model based on equations (8) and (11) also followed the experimental data points well (Fig. 5c). A comparison of the catch comparison curve from the Logit model with that from the empirical model showed nearly identical curves in the length-span were the experimental data have power (Fig. 5), which provides good support for the more informative structural Logit model. Applying equation (2) in Herrmann et al. (2016), the $\mathrm{H}_{0}$ model and the Clogit model demonstrated a relative model likelihood of $6.57 \times 10^{-5 \%}$ and $36.97 \%$, respectively, compared to the Logit model (Table 2). Based on these results, the Logit model was chosen to describe the difference in size selectivity between the conventional and dual sequential codends.

\section{TABLE 2}

\section{FIG. 5}

The catch comparison curve demonstrates a difference in size selectivity between the conventional and dual sequential codends (Fig. 5c). The size selectivity curve in Fig. 6 quantifies the missing size selectivity in the dual sequential codend after the opening of the catch releaser during haul-back. The area above the upper CI in the size selectivity curve provides evidence for the reduced size selectivity in the sequential codend compared to the conventional codend for cod up to $47 \mathrm{~cm}$ (Fig. 6). Specifically, considering the most conservative estimate, cod measuring $20 \mathrm{~cm}$ had $63 \%$ escape probability when located in the conventional codend during haul-back compared to none in the dual sequential codend (Fig. 6, Table 3). Furthermore, for cod measuring $40 \mathrm{~cm}$ the release possibility that would be missing during haul-back with the sequential codend was estimated to affect $51 \%$ of the cod that had not escaped prior but would during haul-back with the conventional codend (Fig. 6, Table 3). For cod measuring $44 \mathrm{~cm}$, which is the minimum target size, the escape probability during haulback was $18 \%$ in the conventional codend (Fig. 6, Table 3).

Applying the upper CI's for the missing haul-back selection curve (Fig. 6) in Eq. 9, enables estimation of the minimum scaling factor which quantifies the minimum relative size selection between the two codends, i.e. the increase in the retention probability in the sequential codend compared to the conventional codend. Cod measuring $20 \mathrm{~cm}$ had an increased retention probability in the trawl with the sequential codend by a factor of minimum 2.71 (Table 3 ). 
359 Furthermore, for cod measuring $40 \mathrm{~cm}$ and $44 \mathrm{~cm}$ the scaling factor was 2.06 and 1.15, 360 respectively (Table 3 ).

$361 \quad$ FIG. 6

362 TABLE 3

363 Although these results demonstrate reduced size selectivity in the sequential codend compared 364 to the conventional codend, this would be a problem only if undersized fish are present in the 365 fishing area, are caught, and fail to escape through the size selective grid or codend meshes 366 before haul-back. When we investigated the population structure retained in the two codends 367 (Fig. 7a, b), we found no significant difference (Fig. 7c). However, it is important to emphasize 368 that these results are case specific and could be due to the lack of undersized fish in the area 369 during the data collection period or to efficient release of undersized fish in the sections anterior 370 to the codend (i.e., size sorting grid and extension piece), as well as during towing.

\section{$371 \quad$ FIG. 7}

372 Total size selectivity in the trawl with the conventional codend and the sequential codend

373 The four control hauls (DS3 in Fig. 1) that were equipped with covers to retain all escapees 374 provided a length-based abundance measure for the cod entering the trawl. The length 375 distribution of the cod retained in the four control hauls (grey line in Fig. 8a, b) differs from the 376 black distribution curves in the figures showing the length distribution of cod retained in the 377 conventional (DS1 in Fig. 1) and sequential codend (DS2 in Fig. 1), respectively. This 378 demonstrates that small cod were present in the area when experimental fishing was conducted. 379 Thus, the four control hauls enabled estimation of the total size selectivity in the trawl with the 380 conventional codend and sequential codend (Fig. 8c, d, Table 4). The fit statistics presented in 381 Table 4 demonstrate a good fit of the model (i.e., the p-value is well above 0.05 , making it 382 highly likely that the observed discrepancy between the experimental catch sharing rates ( $\frac{\sum_{i=1}^{a} \frac{n c_{l i}}{1 c_{i}}}{\sum_{i=1}^{a} \frac{n c_{l i}}{q c_{i}}+\sum_{j=1}^{b} \frac{n f_{l j}}{q f_{j}}}$ and $\left.\frac{\sum_{i=1}^{a} \frac{n s_{l i}}{q s_{i}}}{\sum_{i=1}^{a} \frac{n s_{l i}}{q s_{i}}+\sum_{j=1}^{b} \frac{n f_{l j}}{q f_{j}}}\right)$ and the fitted model is a coincidence). For both codend 384 types, the Logit model provided the lowest AIC value. Comparing the size selection curves in 385 Figure $8 \mathrm{c}$ indicates a minor increase in the retention of fish below the minimum target size in 386 the trawl equipped with the sequential codend. However, based on the total selectivity estimate 387 using the unpaired method (Sistiaga et al. 2016b), no significant difference was detected. 388 Furthermore, the estimated $\mathrm{L}_{50}$ of $64.33 \mathrm{~cm}$ (CI: 56.87-69.81) for the trawl with the 
389

390

391

392

393

394

395

396

397

398

399

400

401

402

403

404

405

406

407

408

409

410

411

412

413

414

415

416

417

418

419

conventional codend and $62.90 \mathrm{~cm}(\mathrm{CI}: 57.69-69.68)$ for the trawl with the sequential codend do not differ significantly (Table 4), and these values lie far above the minimum target size, which in the Barents Sea cod fishery is $44 \mathrm{~cm}$. The $\mathrm{L}_{50}$ values, even when considering the lower CI's, are high compared to previous studies using a flexigrid in combination with a conventional diamond mesh codend (Sistiaga et al. 2009).

FIG. 8

TABLE 4

\section{Discussion}

Brinkhof et al. (2018a) described a dual sequential codend concept that significantly improved the quality of trawl-caught cod compared to a conventional codend. The goal of this study was to address concerns about the potential negative effect on the size selectivity in the trawl if this codend was applied in the fishery. The conventional and anterior segment of the sequential codend were designed similarly, and the water flow in the codends was believed to be similar. The two codends applied were thus assumed to have similar size selective properties until the catch was released into the posterior codend segment in the dual sequential codend during haulback. However, there was a difference of approximately $6 \mathrm{~mm}$ in the mesh size between the anterior segment of the sequential codend and the conventional codend. Since it was the conventional that had the largest mesh size, the results presented in this study are conservative estimates. Therefore, it was reasonable to assume that any difference in the size selectivity in the codends can be attributed the dual sequential codend during haul-back.

During haul-back, the dual sequential codend exhibited a relative increase in the probability of retaining cod up to $47 \mathrm{~cm}$ long compared to the conventional codend (Fig. 6). Although this study demonstrates that the sequential codend had significantly lower size selectivity during haul-back compared to the conventional codend, no difference in the population structure retained in the two codends was detected. This means that the catch pattern between the two codends was not significantly different based on the present data. However, it is important to emphasize that this result is case specific, and may have been caused by lack of undersized fish in the fishing area during data collection or by efficient release through the grid or codend during towing.

A study has demonstrated that the flexigrid, which is the most used sorting grid in the Barents Sea, can be insufficient at releasing undersized fish (Sistiaga et al. 2016a). However, the four 
420

421

422

423

424

425

426

427

428

429

430

431

432

433

434

435

436

437

438

439

440

441

442

443

444

445

446

447

448

449

450

451

452

control hauls conducted (DS3 in Fig. 1) in this study, which retained all cod that entered the trawl, demonstrated that although some undersized fish entered the trawl, most of them managed to escape, either through the grid or through the codend meshes during towing. Estimation of the total size selectivity (grid and codend) indicated that there was only a minor increase in the retention rate for undersized cod with the sequential codend compared to with the conventional codend. The high $\mathrm{L}_{50}$ values obtained with both trawl codends in this study demonstrate low retention of fish below the minimum target size. Even if the sequential codend had led to a significantly lower $\mathrm{L}_{50}$ than the conventional codend, which was not the case, a lower $\mathrm{L}_{50}$ would still be in accordance with the fishery management regulations. The increased catch quality provided by the sequential codend (Brinkhof et al. 2018a) can be considered to be of greater importance than the minor increase in the retention of small cod. Low catch quality can increase the risk of illegal discarding and high-grading (Batsleer et al. 2015). Furthermore, as argued in Madsen et al. (2008) and Brinkhof et al. (2017), fish escaping during haul-back is likely to affect their survivability negatively due to stress-, catch-, or barotrauma-related injuries.

Results of the structural catch comparison model (Eq. 8, 11) applied in this study agreed well with results of the empirical model (Eq. 13). The catch comparison curves from the structural and empirical model were nearly identical in the length span in which the experimental data occurred. The discrepancy between the two modeled curves was likely caused by the difference in the fish entry rates, and it was not significant considering the wide CIs. Because structural models enable estimation of selectivity parameters, the structural model with the best fit was chosen. Structural models are also beneficial due to their robustness for extrapolations outside the range of available length groups that were measured (Santos et al. 2016).

The experimental design with the three different trawl design setups described in Fig. 1 enabled both the estimation of the missing size selectivity in the sequential codend during haul-back, as well as the catch patterns and total size selectivity in the two trawls. Alternating DS1 and DS2 (Fig. 1) enabled estimation of the missing size selection using the paired structural catch comparison model. This model has high statistical power because the catch comparison rate is explicit related to the missing size selection (Eq. 8) without having first to estimate the size selectivity for the two designs. However, the estimation of the total selectivity (Fig. 1) required unpaired analysis, subsequently entailing lower statistical power with wider CI's. Further, the unpaired method relies on the assumption that the size structure of cod entering during the group of test hauls (DS1 and DS2) is on average the same for the group of control hauls (DS3). If this 
453

454

455

456

457

458

459

460

461

462

463

464

465

466

467

468

469

470

471

472

473

474

475

476

477

478

479

480

481

482

483

484

485

assumption is violated, the estimated size selectivity for the test trawls can be biased. Such risk could be particular high under the logistic constrains the sea trials were conducted, i.e. all control hauls were being taken after the all the test hauls instead of as recommendable distributed between them. Such bias in size selection assessment might explain the unusual high $\mathrm{L}_{50}$ values obtained for the total size selection, thus, we need to have some caution with these results. The risk for bias in the catch structure sampling and thereby in the estimation of size selectivity could be avoided by using a twin trawl setup, however, to answer the objectives highlighted in Fig. 1, this would have required six different trawl setups: i) DS1 and DS2, ii) DS1 and DS3, and iii) DS2 and DS3). Compared to the three trawl setups applied in this study which maximizes the utilization each length measurement, a twin setup would have required an increased number of fish measurements. Therefore, it is unsure which design setup would require the lowest number of cod caught and length measured to obtain a specific statistical power for addressing the research objectives. But the twin setup eliminates the risk for bias in the assessment of the size selectivity. The research vessel for our disposal could not handle a twin trawl setup. However, it could be advisable to follow up with a twin setup experiment on another vessel. Preferable, such a follow up experiment should be conducted on a commercial fishing vessel enabling commercial catch sizes with a twin trawl setup as commercial catches affect results (Richards and Hendrickson 2006).

It is important to distinguish between potential size selectivity, which in this case demonstrated significant missing size selectivity in the sequential codend compared to the conventional codend, and the actual size selectivity in the trawl (i.e., actual catch pattern), which in this case did not exhibit any significant difference between codends. This means that although estimation of the relative selectivity demonstrated that there is possibility of increased retention rate of small cod in the sequential codend this requires that they are present in the fishing area and that they do not manage to escape prior being retained in the codend. However, the estimation of the total selectivity demonstrated that, in this case, although the catch patterns revealed the presence of small cod, they likely managed to escape prior being retained in the codend. Thus, despite the missing selectivity, the total selectivity obtained for the trawl equipped with the quality-improving codend revealed a low retention risk for cod below the minimum target size. Hence, this study demonstrates that compared to the conventional codend, the sequential codend has a minor effect on the overall trawl size selectivity. Further studies should investigate if the sequential codend improves catch quality of other species besides from cod, such as haddock (Melanogrammus aeglefinus) and saithe (Polachius virens), without compromising 
486 size selectivity significantly. Additionally, it would be of interest to investigate the applicability 487 of the codend in other fishing gears, such as demersal seine, as well other similar fisheries.

\section{Acknowledgments}

489 This study is part of the project CRISP (Centre of Research-based Innovation in Sustainable 490 Fish Capture and Processing Technology), which is funded by the Norwegian Research Council 491 (Grant No. 203477). We thank the Artic University of Norway for the support of the logistics 492 to perform our sea trails and the Norwegian Directorate of Fisheries for the necessary permits. 493 We also thank the crew of R/V "Helmer Hanssen", technicians Ivan Tatone and Kunuk Lennert, 494 and students Ilmar Brinkhof, Sigrid Aune Mathiesen, and Sindre Vatnehol for help provided 495 during the cruise. We thank the Editor and the anonymous Reviewers for the valuable 496 comments that have improved the manuscript considerable.

\section{References}

498 Akaike, H., 1974. A new look at the statistical model identification. IEEE Transactions on $499 \quad$ Automatic Control, 19: 716-722.

500 Batsleer, J., Hamon, K.G., van Overzee, H.M.J., Rijnsdorp, A.D., Poos, J.J., 2015. 501

512 Burnham, K.P., Anderson, D.R., 2002. Model Selection and Multimodel Inference: A Practical 513 Information-Theoretic Approach, 2nd ed. Springer, New York.

514 Digre, H., Hansen, U. J., Erikson, U., 2010. Effect of trawling with traditional and 'T90' trawl 515 codends on fish size and on different quality parameters of cod Gadus morhua and 
haddock Melanogrammus aeglefinus. Fisheries Science, 76: 549-559, https://doi.org/10.1007/s12562-010

Efron, B., 1982. The jackknife, the bootstrap and other resampling plans. SIAM Monograph No. 38, CBSM-NSF.

Grimaldo, E., Larsen, R.B., Sistiaga, M., Madsen, N., Breen, M., 2009. Selectivity and escape percentages during three phases of the towing process for codends fitted with different selection systems. Fisheries Research, 95(2): 198-205. http://dx.doi.org/10.1016/j.fishres.2008.08.019

Grimaldo, E., Sistiaga, M., Herrmann, B., Larsen, R.B., Brinkhof, J., Tatone, I., 2017. Improving release efficiency of cod (Gadus morhua) and haddock (Melanogrammus aeglefinus) in the Barents Sea demersal trawl fishery by stimulating escape behavior. Canadian Journal of Fisheries and Aquatic Sciences, 75: 402-416, https://doi.org/10.1139/cjfas-2017-0002

Herrmann, B., Eighani, M., Paighambari, S.Y., Feekings, J., 2018. Effect of hook and bait size on catch efficiency in the Persian Gulf recreational fisheries. Marine and Coastal Fisheries, 10: 314-324. https://doi.org/10.1002/mcf2.10031.

Herrmann, B., Krag, L., Frandsen, R., Madsen, N., Lundgren, B., Stæhr, K.J., 2009. Prediction of selectivity from morphological conditions: Methodology and case study on cod (Gadus morhua). Fisheries Research, 97: 59-71.

Herrmann, B., Larsen, R.B., Sistiaga, M., Madsen, N.H.A., Aarsæther, K.G., Grimaldo, E., Ingolfsson, O.A., 2016. Predicting size selection of cod (Gadus morhua) in square mesh codends for demersal seining: a simulation-based approach. Fisheries Research, 184: $36-46$.

Herrmann, B., Mieske, B., Stepputtis, D., Krag, L.A., Madsen, N., Noack, T., 2013 Modelling towing and haul-back escape patterns during the fishing process: a case study for cod, plaice, and flounder in the demersal Baltic Sea cod fishery. ICES Journal of Marine Science, 70(4): 850-863, doi.10.1093/icesjms/fst032.

Herrmann, B., Sistiaga, M., Rindahl, L., and Tatone, I., 2017. Estimation of the effect of gear design changes on catch efficiency: Methodology and a case study for a Spanish longline fishery targeting hake (Merluccius merluccius). Fisheries Research, 185: 153160 . 
547 ICES, 2015. Report of the Arctic Fisheries Working Group (AFWG), 2015, Hamburg, 548 Germany. ICES CM 2015/ACOM: 05, 639 pp.

549 Katsanevakis, S., 2006. Modelling fish growth: model selection, multi-model inference and 550 model selection uncertainty. Fisheries Research, 81(2-3), 229-235 http://dx.doi.org/10.1016/j.fishres.2006.07.002.

552 Krag, L.A., Herrmann, B., Karlsen, J.D., 2014. Inferring fish escape behaviour in trawls based 553 554 555 on catch comparison data: Model development and evaluation based on data from $\begin{array}{lllll}\text { Skagerrak, } & \text { Denmark. } & \text { PLoS } & \text { ONE } & \text { 9(2): }\end{array}$ https://doi.org/10.1371/journal.pone.0088819

Krag, L.A., Herrmann, B., Karlsen, J.D., Mieske, B., 2015. Species selectivity in different sized topless trawl designs: Does size matter? Fisheries Research, 172, 243-249. doi:10.1016/j.fishres.2015.07.010

Larsen R.B., Sistiaga, M., Herrmann, B., Brinkhof, J., Tatone, I., Santos, J., 2018. The effect of Nordmøre grid length and angle on codend entry of bycatch fish species and shrimp catches. Canadian Journal of Fisheries and Aquatic Sciences, https://doi/10.1139/cjfas$\underline{2018-0069}$

Lomeli, M.J.M., Groth, S.D., Blume, M.T.O, Herrmann, B., Wakefield, W., 2018. Effects on the Bycatch of Eulachon and Juvenile Groundfishes by Altering the Level of Artificial Illumination Along an Ocean Shrimp Trawl Fishing Line. ICES Journal of Marine Science, vol. 75, 2224-2234.

567 Madsen, N., Skeide, R., Breen, M., Krag, L.A., Huse, I., Soldal, A.V., 2008. Selectivity in a 568 trawl codend during haul-back operation - an overlooked phenomenon. Fisheries Research, 91: 168-174, http://dx.doi.org/10.1016/j.fishres.2007.11.016

Norwegian Directorate of Fisheries, 2018. J-23-2018: Regulation on Mesh Size, Bycatch and 571 572 Minimum Landing Sizes, etc. During Fishery in the Svalbard Zone (in Norwegian). https://www.fiskeridir.no/Yrkesfiske/Regelverk-ogreguleringer/Jmeldinger/Gjeldende-J-meldinger/J-23-2018. for Statistical Computing, Vienna, Austria. http://www.R-project.org/. 
576 Richards, A., Hendrickson, L., 2006. Effectiveness of the Nordmore grate in the Gulf of Maine Northern shrimp fishery. Fisheries Research, 81(1), 100-106.

Rotabakk, B. T., Skipnes, D., Akse, L., Birkeland, S., 2011. Quality assessment of Atlantic cod (Gadus morhua) caught by longlining and trawling at the same time and location. 580 Fisheries Research, 112, 44-51. http://dx.doi.org/10.1016/j.fishres.2011.08.009

581 Santos, J., Herrmann, B., Mieske, B., Stepputtis, D., Krumme, U., Nilsson, H., 2016. Reducing 582 583 flatfish bycatch in roundfish fisheries. Fisheries Research, 184: 64-73, https://doi.org/10.1016/j.fishres.2015.08.025

584 Sistiaga, M., Brinkhof, J., Herrmann, B., Grimaldo, Langård, L., Lilleng, D., 2016a. Size 585 selection performance of two flexible sorting grid section designs in the Northeast 586 Arctic cod (Gadus morhua) and haddock (Melanogrammus aeglefinnus) fishery. 587 Fisheries Research, 183: 340-351. http://dx.doi.org/10.1016/j.fishres.2016.06.022

588 Sistiaga, M., Herrmann, B., Grimaldo, E., O'Neill, F.G, 2016b. Estimating the selectivity of 589 unpaired trawl data: a case study with a pelagic gear. Scientia Marina, 80:321-327.

590 Sistiaga, M., Herrmann, B., Larsen, R.B., 2009. Investigation of the paired-gear method in 591 selectivity studies. Fisheries Research, 97(3), 196-205.

592 Wileman, D. A., Ferro, R. S.T., Fonteyne, R., Millar, R. B. (Eds.) 1996. Manual of Methods of 593 Measuring the Selectivity of Towed Fishing Gears. ICES Cooperative Research Report $594 \quad$ No. 215. 126 pp. 
Table 1. Details for each haul and haul pair showing codend type, depth, date, towing start time,

2 towing time, number of cod caught, and the sub-sampling factor that compensates for the

3 difference in towing time

4 Table 2. Fit statistics (p-value, deviance, degrees of freedom (DOF)), AIC values, and the

5 relative model likelihood in percentage for the three models evaluated

6 Table 3. Reduced escape probability, and increased retention probability including the lower

7 limit of the scaling factor for cod with $5 \mathrm{~cm}$ length intervals with $95 \%$ CIs for the cod retained

8 in the dual sequential codend compared to the conventional codend

9 Table 4. Size selectivity parameters and fit statistics for the absolute size selectivity in the trawl

10 with the conventional codend and the sequential codend

\begin{tabular}{|c|c|c|c|c|c|c|c|}
\hline Haul No. & Codend type & $\begin{array}{c}\text { Depth } \\
\text { (m) }\end{array}$ & Date & $\begin{array}{l}\text { Start } \\
\text { time } \\
\text { (UTC) }\end{array}$ & $\begin{array}{c}\text { Towing } \\
\text { time } \\
\text { (min.) }\end{array}$ & $\begin{array}{c}\text { Number } \\
\text { of cod }\end{array}$ & $\begin{array}{c}\text { Sub- } \\
\text { sampling } \\
\text { factor }\end{array}$ \\
\hline 1 & Conventional & 368 & 01.03 .2018 & $08: 44$ & 62 & 104 & 1.00 \\
\hline 2 & Dual sequential & 362 & 01.03 .2018 & $10: 47$ & 62 & 282 & 1.00 \\
\hline 3 & Dual sequential & 376 & 01.03 .2018 & $12: 35$ & 60 & 443 & 0.83 \\
\hline 4 & Conventional & 349 & 01.03 .2018 & $15: 46$ & 75 & 172 & 1.00 \\
\hline 5 & Dual sequential & 310 & 02.03 .2018 & $14: 59$ & 45 & 213 & 0.75 \\
\hline 6 & Conventional & 338 & 02.03 .2018 & $16: 30$ & 60 & 116 & 1.00 \\
\hline 7 & Conventional & 351 & 02.03 .2018 & $18: 13$ & 90 & 166 & 1.00 \\
\hline 8 & Dual sequential & 372 & 02.03 .2018 & $20: 40$ & 90 & 196 & 1.00 \\
\hline 9 & Dual sequential & 329 & 03.03 .2018 & $00: 59$ & 90 & 998 & 1.00 \\
\hline 10 & Conventional & 318 & 03.03 .2018 & 09:12 & 75 & 137 & 0.83 \\
\hline 11 & Conventional & 320 & 03.03 .2018 & $11: 24$ & 75 & 154 & 0.83 \\
\hline 12 & Dual sequential & 326 & 03.03 .2018 & $13: 25$ & 90 & 336 & 1.00 \\
\hline 13 & Dual sequential & 297 & 03.03 .2018 & $18: 58$ & 72 & 452 & 1.00 \\
\hline 14 & Conventional & 295 & 03.03 .2018 & $22: 39$ & 36 & 337 & 0.50 \\
\hline 15 & Conventional & 303 & 04.03 .2018 & $02: 55$ & 25 & 525 & 0.83 \\
\hline 16 & Dual sequential & 322 & 04.03 .2018 & $18: 45$ & 30 & 95 & 1.00 \\
\hline 17 & Control & 301 & 05.03 .2018 & $10: 06$ & 61 & 151 & 1.00 \\
\hline 18 & Control & 296 & 05.03 .2018 & $12: 49$ & 30 & 740 & 1.00 \\
\hline 19 & Control & 299 & 05.03.2018 & $18: 14$ & 20 & 180 & 1.00 \\
\hline 20 & Control & 299 & 05.03 .2018 & $20: 15$ & 20 & 311 & 1.00 \\
\hline
\end{tabular}


16 TABLE 2

\begin{tabular}{lccccc}
\hline Model & p-value & Deviance & DOF & $\begin{array}{c}\text { AIC } \\
\text { value }\end{array}$ & $\begin{array}{c}\text { Relative likelihood } \\
\text { (\%) }\end{array}$ \\
\hline H0 & 0.0033 & 115.02 & 77 & 7564.32 & $6.57 \times 10^{-5}$ \\
Empirical & 0.217 & 82.15 & 73 & 7532.99 & 417.87 \\
Clogit & 0.1646 & 85.79 & 74 & 7537.84 & 36.97 \\
Logit & 0.1852 & 85.79 & 75 & 7535.85 & 100 \\
\hline
\end{tabular}

17

18 TABLE 3

\begin{tabular}{lcc}
\hline $\begin{array}{l}\text { Length } \\
\text { (cm) }\end{array}$ & $\begin{array}{c}\text { Escape } \\
\text { probability } \\
(\mathbf{9 5 \%} \text { Cl) }\end{array}$ & $\begin{array}{c}\text { Scaling factor ( } \\
\mathbf{1 . 0} \\
\left.\boldsymbol{r h b _ { c } ( \boldsymbol { l } )}\right)\end{array}$ \\
\hline 20 & $0.99(0.63-1.00)$ & 2.71 \\
25 & $0.99(0.60-1.00)$ & 2.48 \\
30 & $0.97(0.57-1.00)$ & 2.33 \\
35 & $0.95(0.54-1.00)$ & 2.18 \\
40 & $0.89(0.51-1.00)$ & 2.06 \\
44 & $0.82(0.13-0.99)$ & 1.15 \\
50 & $0.65(0.00-0.88)$ & 1.00 \\
55 & $0.47(0.00-0.71)$ & 1.00 \\
60 & $0.29(0.00-0.63)$ & 1.00 \\
65 & $0.16(0.00-0.60)$ & 1.00 \\
70 & $0.09(0.00-0.56)$ & 1.00 \\
75 & $0.04(0.00-0.53)$ & 1.00 \\
80 & $0.02(0.00-0.50)$ & 1.00 \\
85 & $0.01(0.00-0.47)$ & 1.00 \\
\hline & &
\end{tabular}

19

TABLE 4

\begin{tabular}{ccc}
\hline & \multicolumn{2}{c}{ Total selectivity } \\
\cline { 2 - 3 } Parameter & Trawl with & Trawl with sequential \\
conventional codend & codend \\
\hline
\end{tabular}




\begin{tabular}{lcc}
$\mathrm{L}_{50}$ & $64.33(56.87-69.81)$ & $62.90(57.69-69.68)$ \\
$\mathrm{SR}$ & $10.54(6.26-14.91)$ & $12.89(7.49-18.50)$ \\
SP & $0.67(0.48-0.84)$ & $0.76(0.61-0.89)$ \\
p-value & 0.928 & 0.5693 \\
Deviance & 71.21 & 87.02 \\
DOF & 90 & 90 \\
\hline
\end{tabular}


1 Fig. 1. Schematic showing how the three different trawl designs contribute to the objectives.

2 DS1 represents the trawl with the conventional codend, DS2 the trawl with the dual sequential 3 codend, and DS3 the trawl with covers for the collection of the escapees.

4 Fig. 2. Setup of the trawl with the (a) conventional codend and (b) dual sequential codend; (c) 5 Dual sequential codend releaser mounted on the codend segment transition with the rope 6 detached; (d) codend meshes; (e) and (f) show the dual sequential codend during descent and 7 ascent, respectively.

8 Fig. 3. Schematics showing the size selectivity that occurs with the conventional codend $\left(r_{c}(l)\right)$ 9 during (a) towing and (b) haul-back. (c) Size selection in the anterior codend segment of the dual sequential codend during towing, which, due to the codend design, (d) should cease during haul-back when the fish enter the posterior quality-improving codend segment. (The section are not scaled according to each other).

Fig. 4. Map of the area showing where the trawl hauls were conducted. 'c' and 's' denote the towing start position for the haul conducted with the conventional codend and with the sequential codend, respectively, and ' $F$ ' indicates the hauls with covers (i.e., with full retention of all fish).

Fig. 5. (a) Size distribution of the cod retained in the conventional codend (grey) and the dual sequential codend (black). (b) Experimental catch comparison rates (dots) and the $\mathrm{H}_{0}$ model (black solid line) with 95\% CI (black stippled curves). (c) Modeled structural catch comparison rate (black solid curve) with 95\% CI (stippled curves) and the experimental catch comparison rates (dots). The grey curve represents the catch comparison rate from the empirical model with 95\% CI (grey stippled curves).

Fig. 6. Size selection curve (black solid curve) with 95\% CI (stippled curves) showing the missing size selectivity when using the dual sequential codend. The grey stippled lines represent $\mathrm{L}_{05}$ (left line) for the slack meshes in the lower panel and $\mathrm{L}_{95}$ for the slack meshes in the upper panel.

27 Fig. 7. Population structure in the (a) conventional codend and (b) sequential codend; (c) shows the difference in population structure between the two codends. Stippled lines represent 95\% CIs.

Fig. 8. Catch sharing rate for the trawl with the (a) conventional codend and (b) sequential codend. Dots represent the experimental data points, and dashed curves represent CIs. The 
32 distribution curve in black represents the number of cod retained in the codend, whereas the 33 distribution curve in grey represents the cod caught in the four control hauls that retained all 34 fish entering the trawl, including escapees. (c) Absolute size selectivity in the trawl with the 35 conventional codend (grey) and sequential codend (black) (grey stippled line represents the 36 minimum target size of $44 \mathrm{~cm}$ ). (d) Difference in size selectivity between the two codends.

FIG. 1.

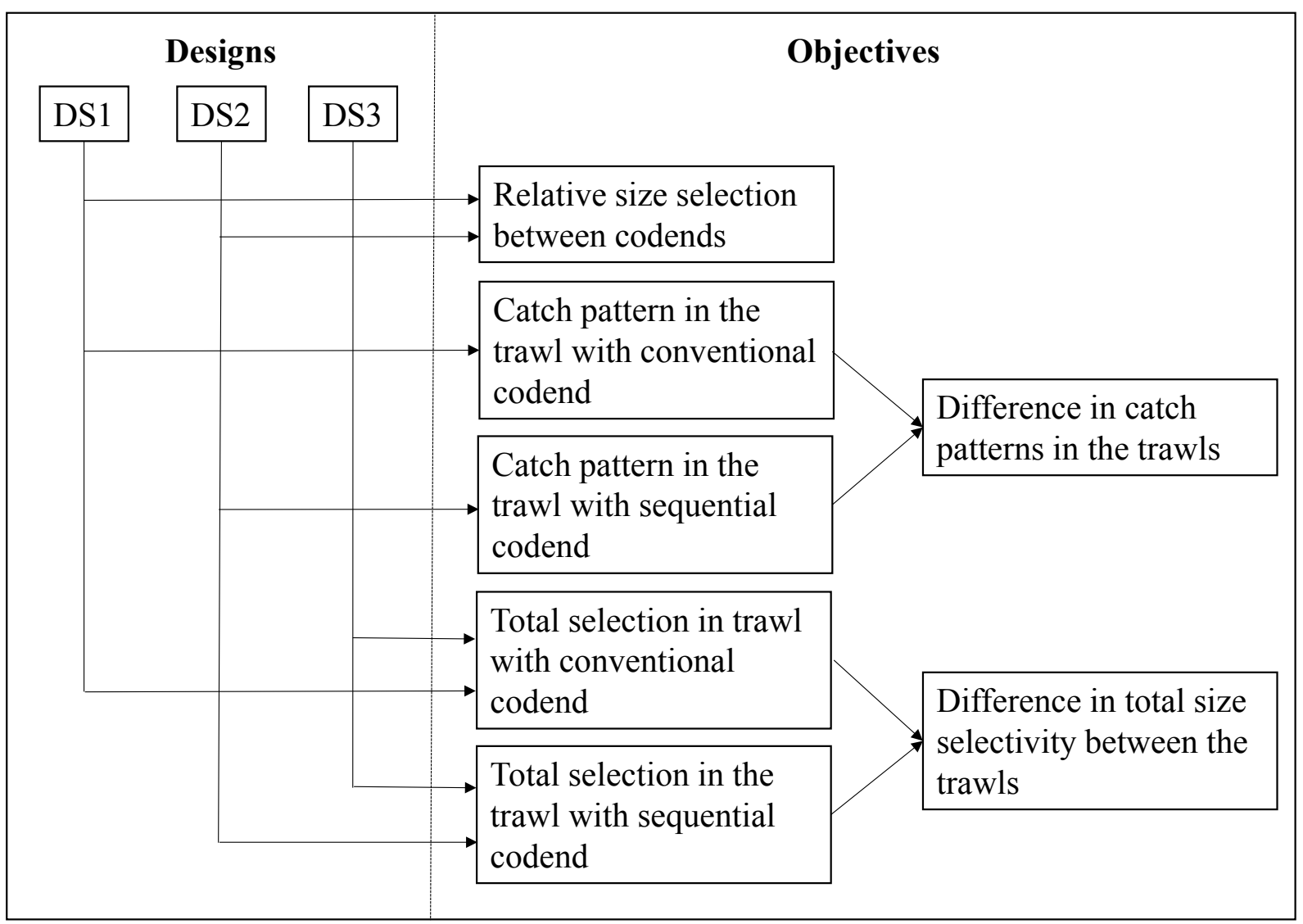


FIG. 2

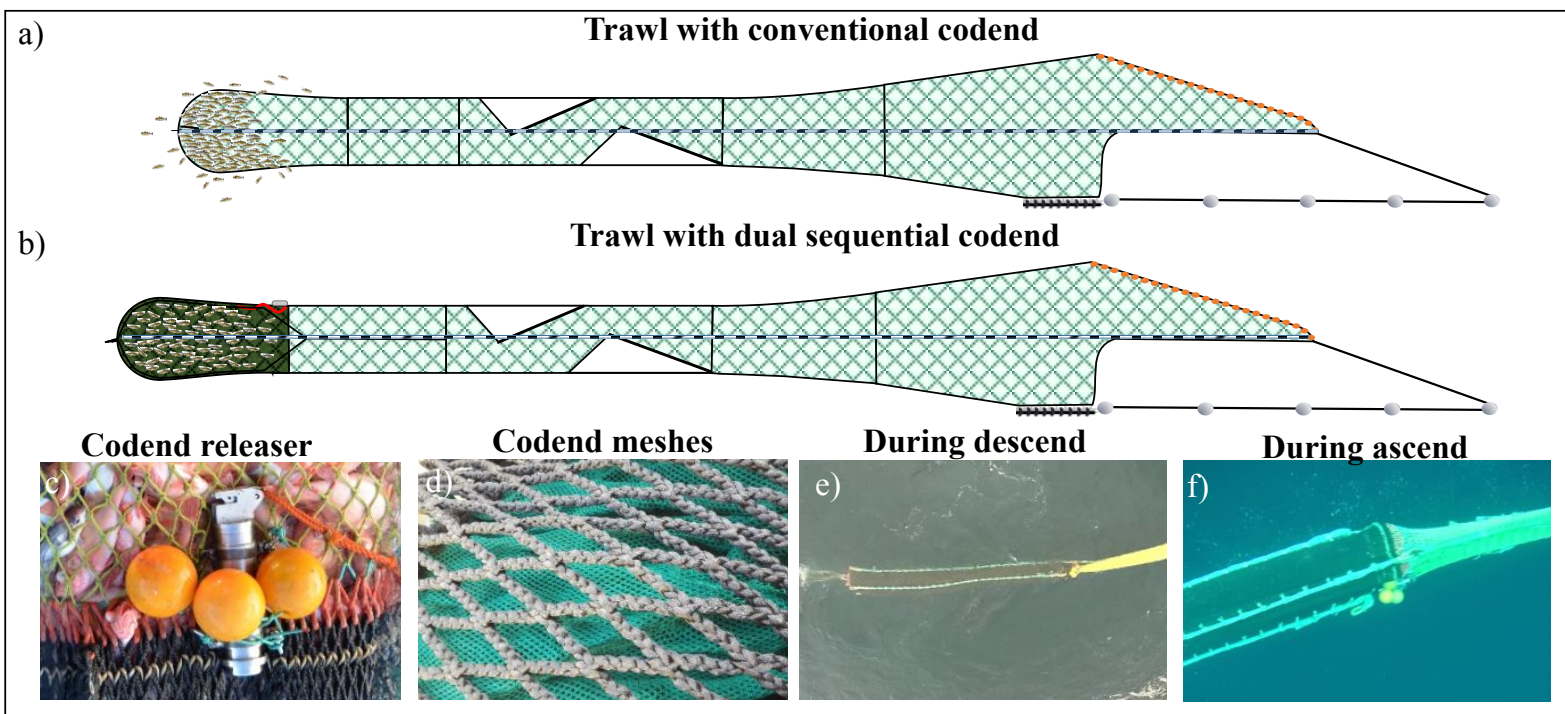


65 FIG. 3

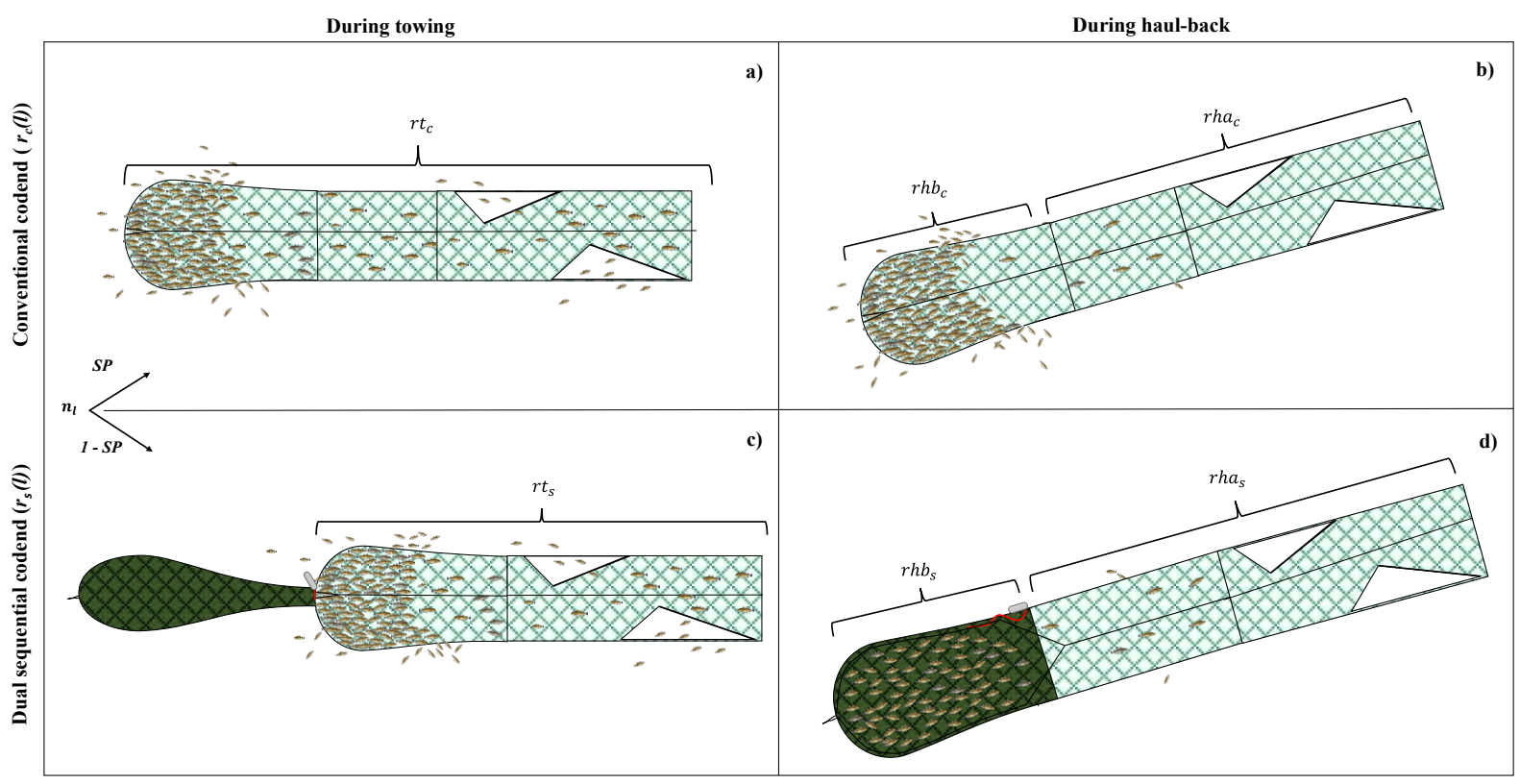


82 FIG. 4

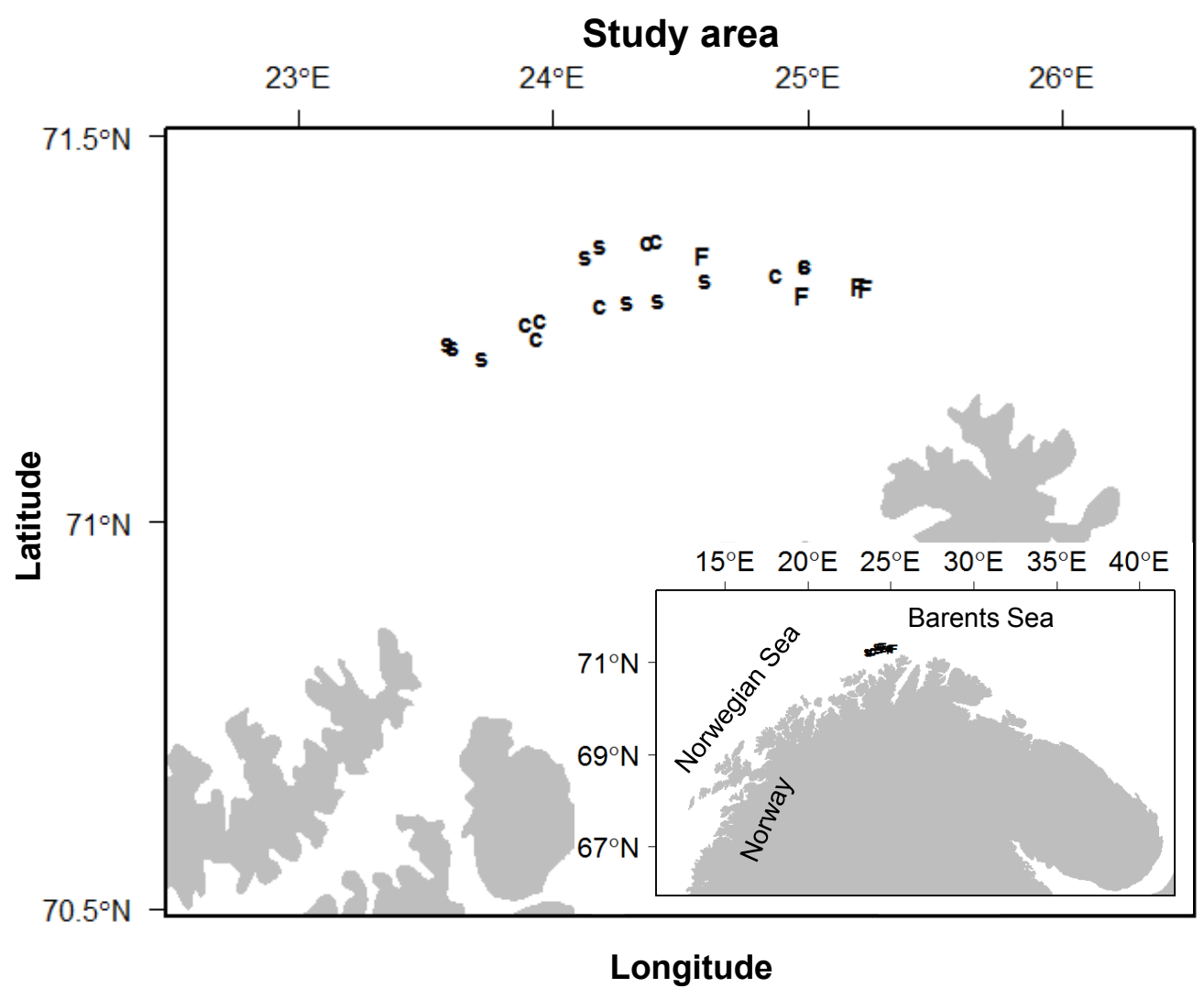

83 
96 FIG. 5

97
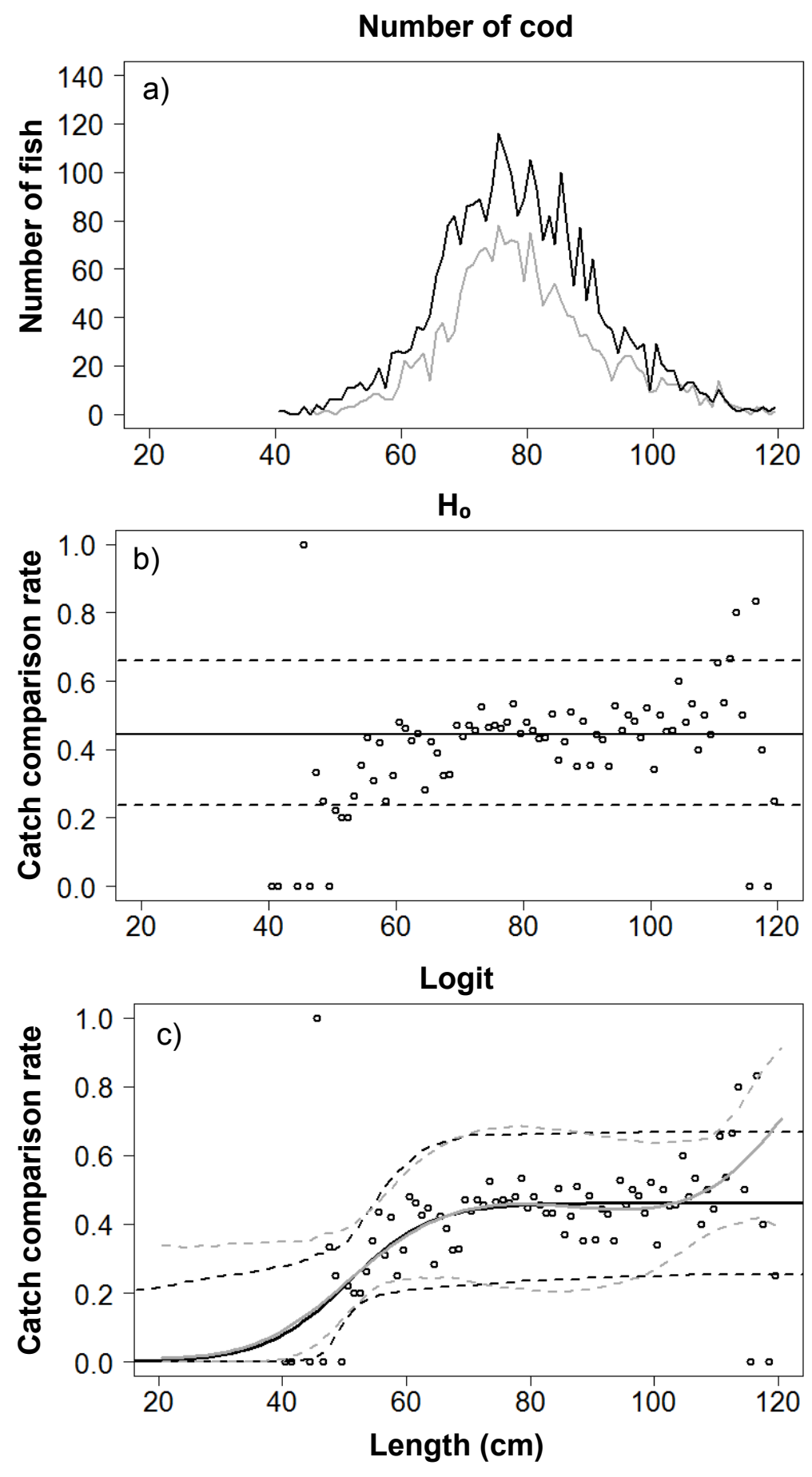

98 
102

103 FIG. 6

\section{Size selection}

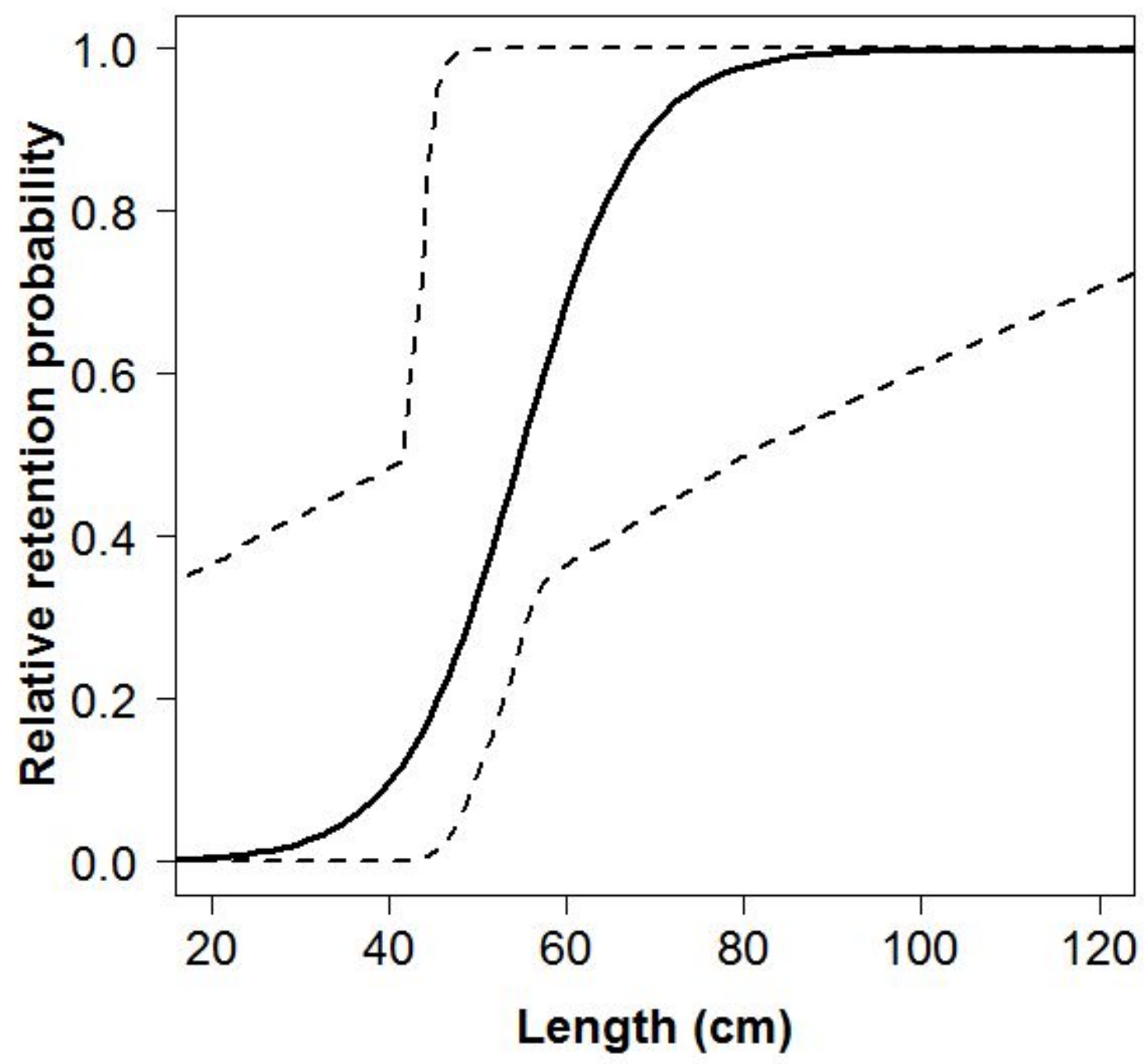




$\begin{array}{ll}11 \\ 12 \\ 13 \\ 14 \\ 15 \\ 16 \\ 17 & \\ 18 & \text { FIG. } 7 \\ & \end{array}$




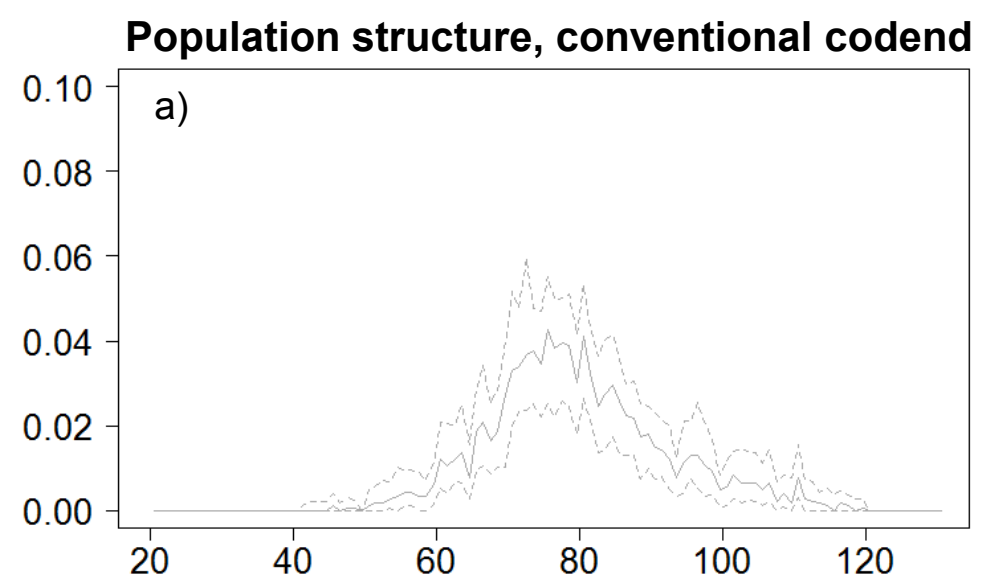

Population structure, sequential codend

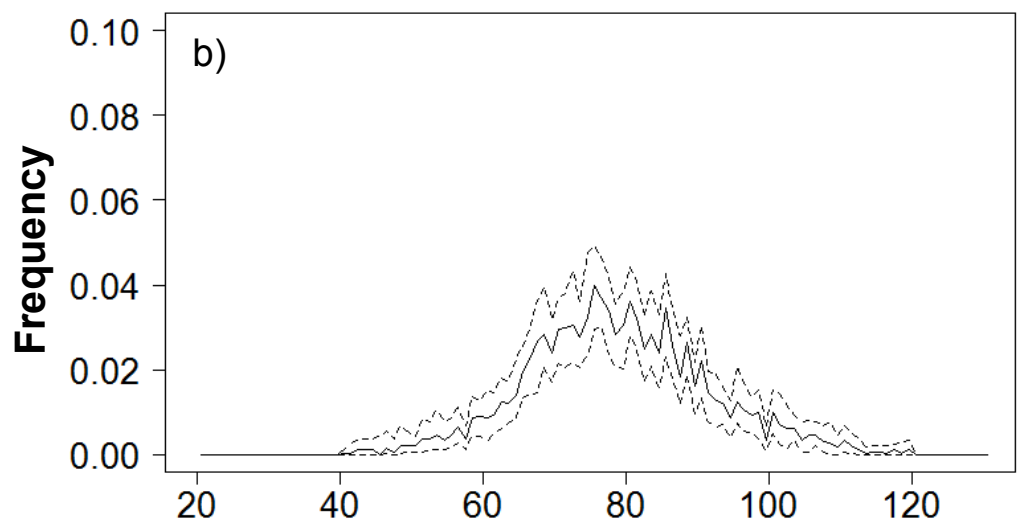

Difference in population structure

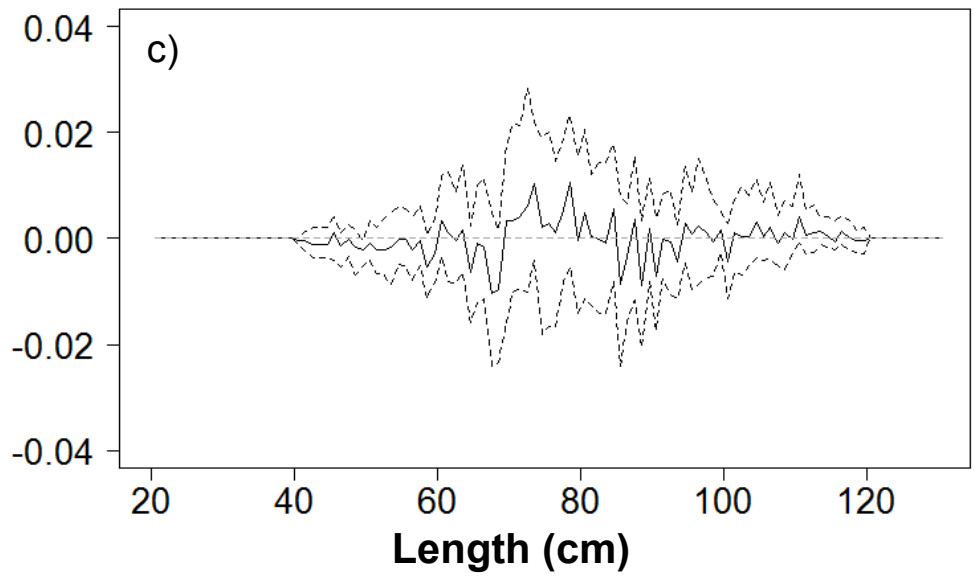



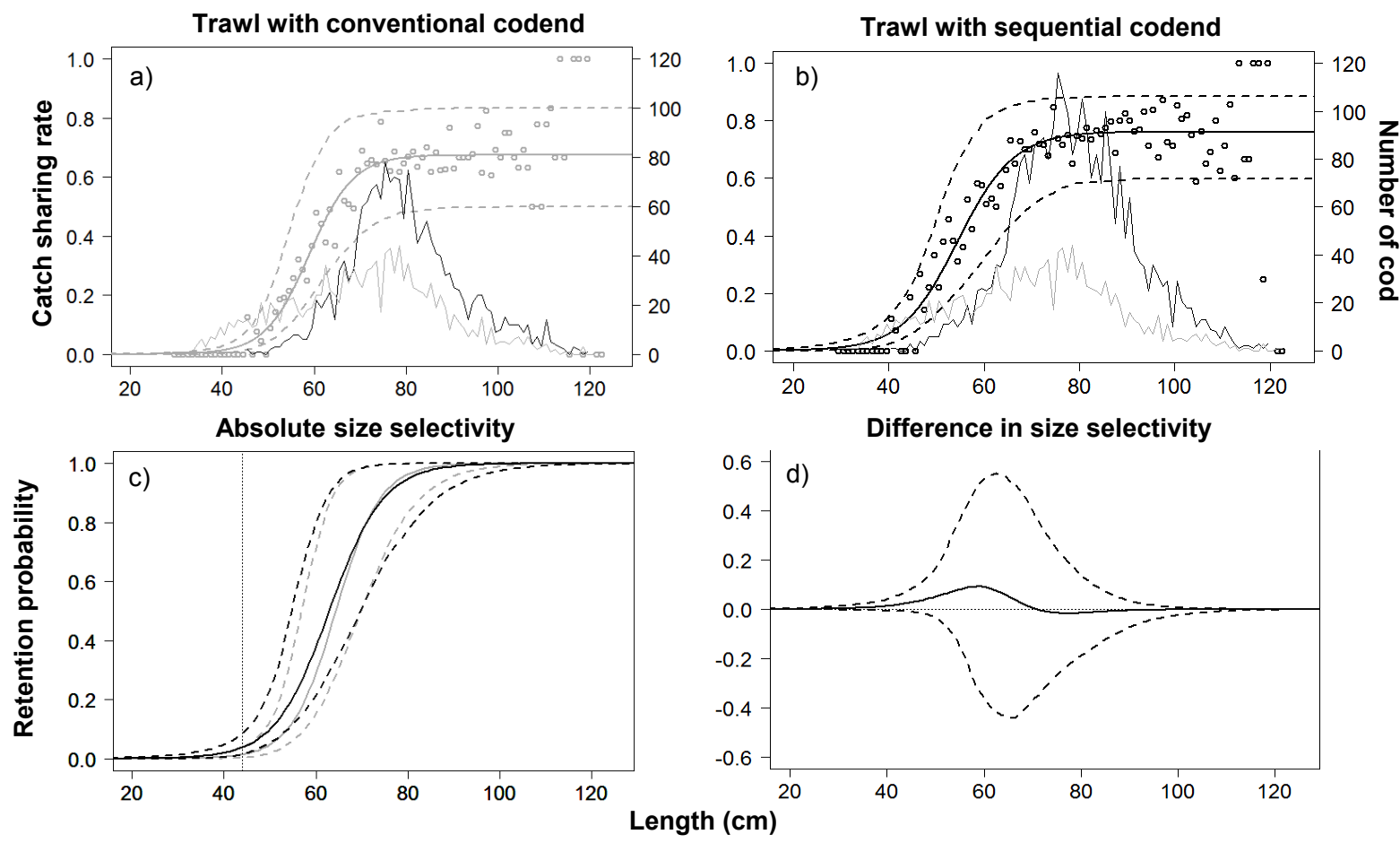

125

Length (cm) 